\title{
Aggression and Resilience in relation to Parenting Styles
}

\author{
ManyaPundir \\ Department of Humanities and Social Sciences, B.A (H) Psychology, Dehradun, Uttrakhand \\ DOI: 10.29322/IJSRP.10.11.2020.p10742 \\ http://dx.doi.org/10.29322/IJSRP.10.11.2020.p10742
}

\begin{abstract}
The purpose of the study is to see the link between two different styles of parenting with aggression and resilience in present adolescents. With the changing world and lifestyle the ways of rearing a child is also changing. Child's advancement in his personality, attitude, and behavior are also dependent on the parents and can influence the aggressive behavior and the resilience or how successfully they are able to adapt in the difficult circumstances. For the study, 120 participants from different schools (Dehradun, India) were selected through convenience sampling technique. Tools used in the study were Adolescent Parenting Attitude Four Factor Questionnaire (APA-FFQ), Buss and Perry Aggression Questionnaire and Brief Resilience Scale. It was a quantitative study and t-test was used to analyze the data. The result indicated that both authoritative and authoritarian styles of rearing had an impact on the child's aggression and that aggression was high in authoritarian style of parenting. Furthermore, there was no impact of both the parenting styles on resilience of a child. It was concluded that two different styles of rearing have an impact on aggression but not on resilience of a child.
\end{abstract}

Index Terms- Parenting styles, aggression, resilience, adolescence

\section{INTRODUCTION}

$\mathrm{T}_{1}$ hroughout history, we have seen that child's advancement in his personality, attitude, and behavior are dependent on the type of parenting also. Parenting is a complicated task; it is the method the parents engage in to raise the child. When a child is born, mostly he sees is his parents and only through his observation he develops a feeling of trust and security. With the passing years, the fast-paced society, and changing lifestyles, the parent-child relationship is also changing. Parenting styles are linked to how the parents themselves were born and raised, their culture, society, and their exposure to different situations in life that in turn affects the child emotionally, socially, physically, intellectually, and spiritually. Parenting styles affect a child's negative emotions and problematic behavior from an early age of 3 years by mothers practicing authoritative parenting styles (Paulussen-Hoogeboom, Stams, Hermanns, Peetsma, $\&$ Wittenboer,2008). According to a sample of US adults parenting styles of high control by mothers have been linked to various mental disorders such as depression, eating, behavioral, attentiondeficit/hyperactivity disorder (ADHD), anxiety disorders, and substance abuse (Eun, Paksarian, \&Merikangas,2018).

This publication is licensed under Creative Commons Attribution CC BY.

http://dx.doi.org/10.29322/IJSRP.10.11.2020.p10742

\section{PARENTING}

Parenting can be elucidated as an act of nurturing or rearing a child in all aspects of socio-emotional, physical and cognitive development since a child is born as a baby till he reaches a level of maturity.

\section{Types of Parenting}

Baumrind (as cited in parenting for brain, 2020) gave three types of parenting styles and Maccoby and Martin (as cited in parenting for brain, 2020) explained the types with bi-dimensional approach i.e., Authoritarian style where the parent has strict rules and high expectation from the child. The autonomy of the child is rejected which might result in the child being more aggressive, with low self-esteem, less creativity, etc. This style is often associated with adolescents developing conduct disorders. A research was conducted to see correlation of authoritarian mothers and their adolescents developing conduct disorder. The result showed that mother's psychological distress and socioeconomic factors contribute to develop conduct disorders in child and a linear correlation was found between the two variables (Thompson, Hollis, \& Richards $\dagger$, 2013). The Authoritative style also has high expectations from the child, but they also give independence to the child to be themselves. This style of parenting is proven to be the finest parenting style when compared to other three. It leads the child to grow in a good environment where he can speak his thoughts clearly with the parents and parents also has autonomy, guidelines, and rules that the child must follow at any cost. A study was done on 6,400 American adolescents that proved that the authoritarian style of parenting guides the adolescents and result in better school performance and engagement in school activities (Steinberg, Lamborn, Dornbusch, \& Darling, 1992). Other than the above mentioned raring styles there are two more raring styles: Permissive style where the parent is overly lenient, they do set rules for the child, but they hardly follow them strictly, and Uninvolved style where the parents do not care about the child they are cold, neglectful and unresponsive to the child's needs. Earlier the parents used to adopt the authoritarian parenting style, however, the trends are changing with the passing years, where greater autonomy is given to the child for private self-expression in activities such as everyday routine, physical outlook, regard and disregard for authority but also minimum freedom given by parents (Rutherfort, 2009).

\section{Aggression}

Aggression is a strong emotion that affects our mood and situation in a variety of cases. American Psychological Association (APA) dictionary of psychology defines aggression as 
to harm a person physically or psychologically and when aggression is to attain a goal or inflict intentional injury it is called hostile aggression. It can be aggressive or instrumental aggression (reaching the goal) or reactive and emotional aggression (the emotional response to the target person).

\section{Social Learning Theory}

Bandura (1973) said that adolescents learn to act impulsive and violent through rewards and punishments, and through observing their models or parents. If a person has been exposed to violence and aggression throughout their life, they are more likely to think it's accepted in their society to be aggressive. Various biological, psychological, and behavioral aggressive factors in childhood related to aggressive behavior in childhood usually increase the likelihood of adolescents developing antisocial behavior in their lives of adolescents and adults (Hill, 2002).Bandura (1997) came up with the social learning theory which was based on the early school of behaviorism; classical conditioning and operant conditioning.

There are four other kinds of aggression i.e., physical aggression which is caused by hitting a person, verbal aggression that is characterized by communicating insulting words or criticizing the other person verbally, hostility when you refuse to accept the attitudes of the other person and have a pessimistic view about them and anger when a person has strong animosity regarding someone.

\section{Resilience}

With increased stress and anxiety in today's world, the adolescents face a lot of negative emotions (anger, fear, disgust, etc.) making it hard for them to be resilient to external factors in the environment. Resilience represents skills of stress coping ability in difficult situations, relationships, etc. American Psychological Association (APA) (2012) help center explains resilience as the phenomenon of reshaping and adjusting successfully in facing distress, misfortune, torment and setback. It involves overcoming and reflecting from difficult circumstances. Our genetics and the environment serve as important factors in building resilience skills. Kim-Cohen, Moffitt, Caspi, \& Taylor(2004) suggested that when 1,116 five-year-old twin pairs were faced with socio-economic distress, factors such as mother's warmth, stimulating activities and a child's outgoing personality all encourage positive adjustment. Furthermore, it stated that both nature and nurture have important role to play along with protective factors in the development of resilience and are influenced by the same. Resilience is seen as a skill and can be acquired and built with time by encouraging positive thinking, practicing on building emotional intelligence, knowing your strength and weaknesses and working to improve them, maintaining a social connection with people, working on one's coping skills. Ken Ginsburg gave 7Cs to build the resilience which are: Competence, Confidence, Connection, Character, Control, Contribution, and Coping (Hurley, 2019)

\section{Types of Resilience}

Hurley, (2019) has categorized the types of resilience into four categories:

Psychological resilience- the ability to work with everyday stress, adapt to the environment when faced with any adversity.
People high on this resilience can remain calm in stressful situations and can move on forward quickly without any long term negative consequences.

Emotional resilience- it refers to how well an individual works with his emotions when faced with adverse situations. Emotionally resilient people are more self-aware and are high on emotional intelligence.

Physical resilience- it is defined as how quickly a person's body recovers and adapts from any injury or accident that they faced. Physically resilient people coping styles might include lots of exercise and meditation.

Community resilience- it suggest the ability of a community or a group together to deal with various adversities like natural disasters, economic downfall, etc.

\section{Adolescence}

Adolescence is a time of an individual that falls somewhere between childhood and adulthood. It is somewhere when a child is around 13-19 years. Various factors contributes in the development of an adolescent like social and emotional aspect where adolescent understands the people and their emotions around him, the way the adolescent is treated in the family and his environment, the nutrition that his body gets to work well, the socio-economic status the family has, the education and learning that he adopts, etc. During this crucial stage of life adolescents may not agree with the parents and might have different beliefs. A study done on adolescents and parents to see the parental authority and the parenting styles suggest that they both see themselves differently; adolescents perceived their parents being more permissive and authoritarian and parents viewed themselves as being more authoritative. Also, suggesting that both the authority and styles of parenting were because of emotional autonomy and conflict between parent and adolescents (Smetana, 1995).

Adolescents' period is also interrelated to psychopathic and antisocial behavior that they learn from observing their parents and environment.(Silva \& Stattin, 2016) did a study using the multiple regressions to see the relation between parenting and psychopathy on children and mothers. The results showed a linear interaction between the same.

\section{LITERATURE REVIEW}

Talking about the rearing styles various factors can affect the child's experiences and the most part of development. Aggression and emotions can be learned through watching their parents or older people that they admire or the environment they are raised in. Llorca, Richaud, \& Malonda, (2017) did a cross-sectional study to see the effects of styles of parenting on pro-social and behavior inclined towards aggression through factors of empathy and stability of emotions in offenders and adolescents who were not involved in any crime in Valencia. Results showed that the variable of emotion acted as intermediate in adolescents who were not involved in crime, but in offender adolescents support and negligence had a direct effect on behavior inclined towards aggression in a negative way and in contrast positively affected pro social behavior and of permissiveness o pro-social behavior in a negative way. Another study done by Llorca-Mestre, SamperGarcía, Malonda-Vidal, \& Cortés-Tomás,(2017) observed role of various type of rearing by parents and attachment towards peers 
and whether it predict emotional instability in adolescents with variables such as anger, empathy and ways to cope with anger. The result was examined separately for males and females through regression and showed that parenting styles and peer attachment was significantly predicting the emotional instability in adolescents. The authoritative style of rearing brings a good result and children are less aggressive. De la Torre-Cruz, GarcíaLinares, \& Casanova-Arias, (2014)did a study to analyze the physical and verbal aggression in adolescents shown towards their friends with the styles of parenting of not just the mothers', but also the fathers'. Results indicated an authoritative style of parenting by various parents showed scores that were low in aggressive behavior as compared to the parents who practiced an authoritarian style of rearing. There was also seen a difference in gender (males) being high on aggression than girls.

When talking about different rearing styles and taking them individually it is seen that the harsh or the Authoritarian parenting can make a child grown up to more aggressive than other styles of parenting. In the study by Chang, Schwartz, Dodge,\& McbrideChang, (2003) who created a model to see the role of emotional regulation in concerning harsh parenting (direct and indirect) and how all of it effects child aggression in school. The sample was 325 Chinese adolescents. The result showed that mothers' harsh parenting affected both the genders, where as fathers' harsh parenting style affected just the male adolescents and had stronger affect on child's aggression. Strict parenting adopted by mothers' had an impact on the child's emotion stability more when compared with strict parenting adopted by fathers'. The study also suggested that negative emotions serve as precipitating factor leading to family anxiety and problem in adjusting for a child. Similar study done by Azimi, Vaziri, \& Kashani, (2012) studied out to see the connection in mothers' side of parenting style and aggression that forms the behavior of the child with sample of 380 high school students (males and females) of Tehran. The result showed that the authoritarian style of rearing had favorable impact and it formed the behavior that is aggressive in a child. Furthermore, it was noted that authoritative and indulgent styles of rearing were not favorable and did not have a connection with aggression.

Various factors contribute to build our resilience, if a child has seen a lots of hardships in life he'll be more resilient, but that is not always true it depends on the individually and the environment the child is raised up in Barnová, Tamášová,\& Krásna, (2019) contemplated a paper to provide a review of literature on parents' negative behavior and the role of resilience. The traditional desk research method was used. The conclusion suggested that neglect, domestic violence, abuse can affect the child negatively making him less resilient. Moreover, other protective factors such as schools, institutions, and support groups have a huge part to provide support like, developing their coping strategies and encouraging resilience in a child when dealing with risks. The different parenting styles bring up different resilient children Azarnioshan, Naderi, Shojaee, \& Asghariganji, (2019) examined a study to see the intermediate role of resilience between different styles of parenting and how well they controlled their anger in secondary school of Iran. The result displayed parents who were involved in authoritative style of rearing adolescents had a favorable medium of controlling anger and resilience in child whereas the authoritarian style of rearing adolescents had an unfavorable medium of controlling anger and resilience in child. Also, resilience was a positive medium for aggression. A similar study done by Kritzas, \& Grobler, (2005) was conducted on 360 English speaking adolescents to examine the connection between different styles of parenting and resilience. The authoritative style of parenting displayed a connection with resilience of white and black adolescents. Also, a favorable connection with fathers' authoritarian style of parenting and coping strategies focused on our emotions in white learners. In contrast, the authoritarian style of parenting was connected to psychological disturbances.

\section{METHODOLOGY}

Aim

To study the aggression and resilience of adolescents in relation to parenting styles.

\section{Hypotheses}

Considering the current sample and the variables certain hypotheses were made for the study:

1. There will be significant difference in the aggression level between authoritative parenting styles and authoritarian parenting styles.

2. There will be a significant difference in the resilience level between authoritative parenting styles and authoritarian parenting styles.

\section{Variables}

Aggression and resilience were the dependent variables that were studied across the independent variable that is parenting styles.

\section{Sample and Sampling Technique}

For the study, adolescents of 15-18 years were chosen from 2 different schools in Dehradun, India. The sample consisted of both boys and girls. The sample was selected by using convenience sampling technique where the adolescents who were easily available were included in the study.

\section{Tools used}

For measuring the aggression, resilience and parenting styles, three different questionnaires were used:

1. Adolescents Parenting Attitude Four Factor Questionnaire (APA_FFQ) by Shyny T.Y (2017)

2. The Buss and Perry Aggression Questionnaire (BPAQ) (1992)

3. The Brief Resilience Scale by Smith and Colleagues (2008)

\section{Procedure}

Initially 120 school going adolescents of $15-18$ years of age were included in the sample. Out of the total 120 adolescents, 109 were taken into consideration who reported authoritarian and authoritative parenting styles. The remaining 11 who reported permissive and uninvolved parenting styles were rejected due to very little in number. The participants had their free will to participate in the study. They were contacted virtually and were asked to fill an online google form which consisted of total 75 questions from all three tools used in this research. The subjects were assured for the confidentiality of their names and responses. 


\section{Statistical Analysis}

The data was treated statistically by using Statistical Package for the Social Sciences (SPSS). In order to test the hypotheses independent t-test statistical device was used.

\section{RESUlTS AND DisCUSSIONS}

The idea behind this research was to see the difference of aggression and resilience in adolescents with the authoritative and authoritarian type of rearing style.

\section{Table 1: Independent t-test scores of Parenting Styles and Aggression}

\begin{tabular}{lllllllll}
\hline & Parentin & & \multicolumn{9}{c}{$S E$} \\
& $\mathrm{~g}$ & $n$ & $M$ & $S D$ & $M$ & $t$ & $d f$ & $p$ \\
\hline Aggres & Authorit & 7 & 82. & 15. & 1.8 & - & 10 & 0.0 \\
sion & ative & 0 & 44 & 61 & 7 & 2.1 & 7 & 35 \\
& & & & & & $3^{*}$ & & \\
& Authorit & 3 & 89. & 15. & 2.5 & & & \\
& arian & 9 & 1 & 73 & 2 & & & \\
\hline
\end{tabular}

$*<\mathrm{p}=0.05$

An independent t-test was carried out to measure aggression in authoritative parenting style $(\mathrm{n}=70)$ and the authoritarian parenting style $(\mathrm{n}=39)$. There was a significant difference in the scores for authoritative style of parenting $(\mathrm{M}=82.44, \mathrm{SD}=15.61)$ and authoritarian style of parenting $(\mathrm{M}=89.1, \mathrm{SD}=15.73)$ with $\mathrm{t}$ ($2.13)=107, p=0.035$. This suggests that the two parenting styles have a significant impact on aggression. Specifically, aggression is high in authoritarian style of parenting when compared with an authoritative style of parenting.

Results of the study explained that there was a distinction in the aggression level of the authoritative type of rearing used by parents and authoritarian type of rearing. Aggression was seen high in the authoritarian parenting style when compared with an authoritative parenting style. The authoritative type of rearing is considered the best parenting style mostly because the parents have a high demand from the child, but they also give the child their freedom to express themselves because of which the child becomes independent, cooperative, good decision-maker and high achiever whereas, in authoritarian parenting style the child cannot express himself and has to abide by the rules of authority. He may be high achiever but he might hide his emotions resulting in aggression. One reason for this could be that parents who are democratic or warm and form a secure attachment style in the early years of child development in which there is care, warmth, and love. They communicate with the child and are emotionally present for them. On the other hand authoritative parenting style form an insecure attachment style where the child might not be able to comprehend his emotions and is more dependent and reluctant on the parent for care. The child might grow up to be shy or rigid in expressing himself. Zeinali, Sharifi, Enayati, Asgari, \& Pasha (2011) did research that highlighted authoritative and lenient styles of parenting were connected to form a secure attachment, high in monitoring and controlling emotions which declined the probability of addiction vulnerability, unlike authoritarian and neglectful parenting styles which were connected to anxious attachment style, low in self-regulation and increased probability of addiction susceptibility.

The other reason why adolescents experiencing authoritarian parenting style are more aggressive can be because these adolescents don't have clear self-concept and self-esteem. After all, their parents use coercive methods to deal with the child, they force them to act under what is right to them because of which child gets confused and becomes dependent on the parents on how to behave. They are cold-hearted, cruel, and harsh on the child with no positive encouragement to motivate the child to do something. They become impatient and cannot engross themselves fully in a task which might make them frustrated making them more vulnerable to anxiety, depression, or any other mental disorder. While, authoritative parenting style adolescents have a clear concept and good emotional understanding, empathy, they know how to manage their life's problems more patiently and they are more likely to preserve in the task that's assigned to them. Rather than getting frustrated they channelize all their potential to something they feel they are good at, explaining why they may be less aggressive and less anxious or stressed. An academic work to perceive the impact of the three parenting styles on a sense of self, mental health, and standard of living on adolescents the result showcased the authoritative style of parenting had a positive impact on adolescents as they had better sense of self and selfworth, a better standard of living and less mental health problems when compared with authoritarian and permissive parenting style. (Nairaki \& Rahimi, 2013)

\section{Table 2: Independent t-test scores of Parenting Styles and Resilience.}

\begin{tabular}{lllllllll}
\hline & & & \multicolumn{9}{c}{$S E$} \\
& Parenting & $n$ & $M$ & $S D$ & $M$ & $t$ & $d f$ & $p$ \\
\hline Resilie & Authorita & 7 & 3.0 & 0.5 & 0.0 & 0.53 & 10 & 0.5 \\
nce & tive & 0 & 8 & 5 & 7 & $3^{*}$ & 7 & 95 \\
& Authorita & 3 & 3.0 & 0.7 & 0.1 & & & \\
& rian & 9 & 1 & 1 & 1 & & & \\
\hline
\end{tabular}

$*<\mathrm{p}=0.05$

An independent t-test was carried out to measure resilience in the authoritative style of parenting $(n=70)$ and authoritarian style of parenting $(\mathrm{n}=39)$. There was no significant difference in the scores for authoritative parenting style $(\mathrm{M}=3.08, \mathrm{SD}=0.55)$ and authoritarian parenting style $(\mathrm{M}=3.01, \mathrm{SD}=0.71)$ with $\mathrm{t}(0.533)$ $=107, \mathrm{p}=0.595$. This suggests that the two parenting styles do not significantly impact resilience of the adolescents.

Resilience is a practiced skill that develops overtime and helps the individual to tackle various difficult circumstances. Both, authoritarian and authoritative parenting styles did not affect the resilience level of the adolescents. One possible reason for this could be the other environmental factors such as increased technological advancement and the use of smartphones and screens. That can act as a constant distraction, make a person sleep deprived. Various studies propose the exposure to blue screens can result in lower melatonin production, hamper our eyes, interrupting circadian rhythm, and results in poor sleep causing the individual to be less resilient and high in anxiety. The digital era has a lot of impact on our work-life balance and reduced 
connection with parents, friends, and romantic partners. Furthermore, we face the fear of missing out and often compare ourselves with other individuals (Harrison \& Lucassen, 2019).

Other reason for the child to not be resilient can be because both parents of authoritative parenting and authoritarian parenting styles strive for high expectations from the child meaning they strive for the child to be a perfectionist and excel in his field which might make a child feel less motivated and he might even get overwhelmed and stressed when he's not able to achieve great heights that their parents want to make them less resilient in dealing with academics. Klibert et. al. (2014) did a study that highlighted the relation among perfectionism, resilience, and distress. The result showed that resilience played a mediating role between distress and prescribed perfectionism.

On the bases of the discussion of results, there are number of things which can come up as suggestions to build a better relationship between children and their parents. The family can consult a professional such as a psychologist who deals with problematic family relationships, or those having difficulty to adjust in the society in order to resolve related issues. The psychologist can help the parents in practicing the right ways of parenting and build an environment in which the child can flourish. They can also help the adolescents release their frustrations through counseling and therapeutic interventions so that they become less aggressive and build more resilience.

\section{CONCLUSION}

It was concluded that there was a significant difference in levels of aggression in adolescents who reported authoritative and authoritarian styles of rearing and aggression was found more in authoritarian parenting style when compared with authoritative parenting style. Contrarily, there was no significant difference in the resilience level of authoritative and authoritarian styles of rearing. The results of the study indicate that there is a need to deal with issues like problematic family relationship, maladjustments, frustrations etc. by consulting the related professionals.

\section{LIMITATIONS AND SUGGESTIONS}

There are number of limitations observed in this study for which suitable suggestions have been provided. First of all, the present study focused on just two parenting styles i.e. authoritarian and authoritative. Secondly, the study did not look at any other demographical factor other than the age of the adolescents. Further, the sample size was small and limited schools were included in the study and the study was done using online google forms only. On the bases of limitations observed, it is suggested that including permissive and uninvolved styles of rearing would get us more representative results. The results might have been more representative of the population if the subjects would have been contacted physically, from more number of schools and if wider demographic factors were included such as socio-economicstatus, areas, etc. It is also suggested that the study can be replicated on children and young adult.

\section{REFERENCES}

[1] American Psychological Association (2012). Building your resilience Retrieved May 7, 2020, from https://www.apa.org/topics/resilience

[2] APA Dictionary of Psychology. (n.d.). Retrieved from https://dictionary.apa.org/aggression

[3] Azarnioshan, B., Naderi, H., Shojaee, A. A., \&Asghariganji, A. (2019). The Mediating Role of Resilience in the Relationship Between Perceived Parenting Styles and Anger Management. International Journal of School Health, 6(3). doi: 10.5812/intjsh.95048

[4] Azimi, A. L., Vaziri, S., \&Kashani, F. L. (2012). Relationship between Maternal Parenting Style and Childs Aggressive Behavior. Procedia - Social and Behavioral Sciences, 69, 1276-1281. doi: 10.1016/j.sbspro.2012.12.062

[5] Barnová, S., Tamášová, V., \&Krásna, S. (2019). The Role of Resilience in Coping with Negative Parental Behaviour, ActaEducationisGeneralis, 9(2), 93-106. doi: https://doi.org/10.2478/atd-2019-0010

[6] Baumrind D. (1967) Child care practices anteceding three patterns of preschool behavior. Genet PsycholMonogr. 1967;75(1):43-88. https://www.ncbi.nlm.nih.gov/pubmed/6032134

[7] Chang, L., Schwartz, D., Dodge, K. A., \&Mcbride-Chang, C. (2003). Harsh Parenting in Relation to Child Emotion Regulation and Aggression. Journal of Family Psychology,17(4), 598-606. doi:10.1037/0893-3200.17.4.598

[8] De la Torre-Cruz, M. J., García-Linares, M. C., \& Casanova-Arias, P. F. (2014). Relationship between parenting styles and aggressiveness in adolescents. Electronic Journal of Research in Educational Psychology, 12(1), 147-169. https://doi.org/10.14204/ejrep.32.13118

[9] Eun, J. D., Paksarian, D., He, J. P., \&Merikangas, K. R. (2018). Parenting style and mental disorders in a nationally representative sample of US adolescents. Social psychiatry and psychiatric epidemiology, 53(1), 11-20. https://doi.org/10.1007/s00127-017-1435-4

[10] Harrison, Gini., \&Lucassen, Mathijs., (2019) Stress and anxiety in the digital age: The dark side of technology. Retrieved May 07, 2020, from https://www.open.edu/openlearn/health-sports-psychology/mentalhealth/managing-stress-and-anxiety-the-digital-age-the-dark-sidetechnology

[11] Hill, J. (2002). Biological, psychological and social processes in the conduct disorders. Journal of Child Psychology and Psychiatry, 43(1), 133-164. https://doi.org/10.1111/1469-7610.00007

[12] Hurley, K. (2019). What Is Resilience? Definition, Types, Building Resiliency, Benefits, and Resources: Everyday Health. Retrieved May 03, 2020, from https://www.everydayhealth.com/wellness/resilience/

[13] Kim-Cohen, J., Moffitt, T. E., Caspi, A., \& Taylor, A. (2004). Genetic and Environmental Processes in Young Adolescents's Resilience and Vulnerability to Socioeconomic Deprivation. Child Development,75(3), 651 668. doi:10.1111/j.1467-8624.2004.00699.x

[14] Klibert, J., Lamis, D. A., Collins, W., Smalley, K. B., Warren, J. C., Yancey, C. T., \&Winterowd, C. (2014). Resilience Mediates the Relations Between Perfectionism and College Student Distress. Journal of Counseling \& Development,92(1), 75-82. doi:10.1002/j.1556-6676.2014.00132.x

[15] Kritzas, N., \&Grobler, A. A. (2005). The relationship between perceived parenting styles and resilience during adolescence. Journal of Child \& Adolescent Mental Health, 17(1), 1-12. doi: 10.2989/17280580509486586

[16] Llorca, A., Richaud, M. C., \&Malonda, E. (2017). Parenting Styles, Prosocial, and Aggressive

[17] Behavior: The Role of Emotions in Offender and Non-offender Adolescents Frontiers in Psychology, 8. doi: 10.3389/fpsyg.2017.01246

[18] Llorca-Mestre, A., Samper-García, P., Malonda-Vidal, E., \& Cortés-Tomás, M. T. (2017).

[19] Parenting style and peer attachment as predictors of emotional instability in adolescents. Social Behavior and Personality: An International Journal,45(4), 677-694. doi: 10.2224/sbp.5363

[20] Maccoby EE, Martin JA. (1983) Socialization in the Context of the Family: Parent-Child Interaction. In: Handbook of Child Psychology. Socialization, Personality, and Social Development.

[21] Masten, A. S., Cutuli, J. J., Herbers, J. E., \& Reed, M.-G. J. (2009). Resilience in development.

[22] In S. J. Lopez \& C. R. Snyder (Eds.), Oxford library of psychology. Oxford handbook of positive psychology (p. 117-131). Oxford University Press. 
[23] Parenting for brain (2020). 4 Parenting Styles - Characteristics And Effects, (n.d.). Retrieved May 6, 2020, from https://www.parentingforbrain.com/4baumrind-parenting-styles/

[24] Paulussen-Hoogeboom, M. C., Stams, G. J., Hermanns, J. M., Peetsma, T. T., $\&$ Wittenboer, G.

[25] L. (2008). Parenting Style as a Mediator Between Adolescents's Negative Emotionality and Problematic Behavior in Early Childhood. The Journal of Genetic Psychology,169(3), 209-226. doi:10.3200/gntp.169.3.09-226

[26] Pennock, S. F. (2019, November 17). Resilience in Positive Psychology: Bouncing Back \& Staying Strong. Retrieved from https://positivepsychology.com/resilience-in-positive-psychology/

[27] RezaiNiaraki, F., \&Rahimi, H. (2013). The impact of authoritative, permissive and authoritarian behavior of parents on self-concept, psychological health and life quality. European Online Journal Of Natural And Social Sciences, 2(1), pp.78-85. Retrieved from http://europeanscience.com/eojnss/article/view/24

[28] Rutherfort M. B., (2009) Adolescents's autonomy and responsibility: An analysis of childrearing advice. Qualitative Sociology., 32(4):337-353. DOI:10:1007/s11133-009-9136-2

[29] Silva, T. C., \&Stattin, H. (2016). The moderating role of parenting on the relationship between psychopathy and antisocial behavior in adolescence. Development and psychopathology, 28(2), 505-515. https://doi.org/10.1017/S0954579415001121
[30] Smetana J. G. (1995). Parenting styles and conceptions of parental authority during adolescence. Child development, 66(2), 299-316. https://doi.org/10.1111/j.1467-8624.1995.tb00872.x

[31] Steinberg, L., Lamborn, S. D., Dornbusch, S. M., \& Darling, N. (1992). Impact of Parenting Practices on Adolescent Achievement: Authoritative Parenting, School Involvement, and Encouragement to Succeed. Child Development,63(5), 1266. doi:10.2307/1131532

[32] Thompson, A., Hollis, C. \& Richards†, D., (2003) Authoritarian parenting attitudes as a risk for conduct problems. European Child \& Adolescent Psychiatry 12, 84-91 (2003). https://doi.org/10.1007/s00787-003-0324-4

[33] Zeinali, A., Sharifi, H., Enayati, M., Asgari, P., \& Pasha, G. (2011). The mediational pathway among parenting styles, attachment styles and selfregulation with addiction susceptibility of adolescents. Journal of research in medical sciences: the official journal of Isfahan University of Medical Sciences, 16(9), 1105-1121.

\section{AUTHORS}

First Author - ManyaPundir, Department of Humanities and Social Sciences, B.A (H) Psychology, Dehradun, Uttrakhand 